\title{
Extracto de canela sobre las características de fermentación ruminal en sistemas
} in vitro

\section{Cinnamon extract on the characteristics of ruminal fermentation in in-vitro systems}

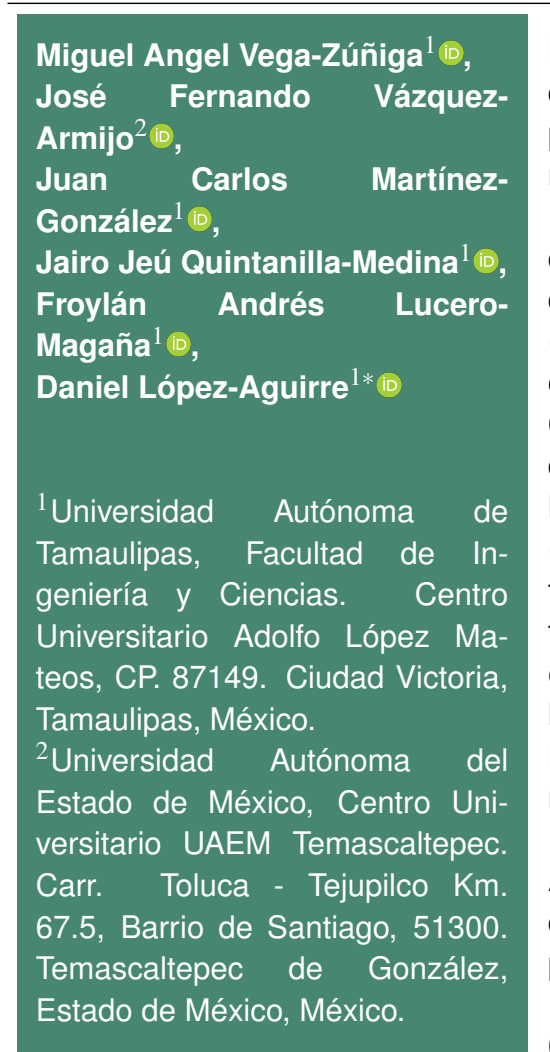

*Autor de correspondencia: dlaguirre@docentes.uat.edu.mx

\section{Artículo científico}

Recibido: 27 de noviembre 2020 Aceptado: 29 de octubre 2021

Como citar: Vega-Zúñiga MA Vázquez-Armijo JF, MartínezGonzález JC, Quintanilla-Medina JJ, Lucero-Magaña FA, LópezAguirre D (2021) Extracto de canela sobre las características de fermentación ruminal en sistemas in vitro. Ecosistemas y Recursos Agropecuarios 8(3): e2763. DOI: 10.19136/era.a8n3.2763
RESUMEN. Se realizaron dos experimentos con el objetivo de evaluar el efecto de diferentes dosis de adición de extracto de Cinnamomum verum en una dieta para corderos sobre los parámetros de fermentación in vitro y la degradabilidad ruminal. En el primer experimento se realizó la técnica de producción de gas in vitro (PG) a una dieta para corderos adicionada con 0.0, 0.6, 1.2 y $1.8 \mathrm{~mL} \mathrm{~g}^{-1}$ de MS de extracto de $C$. verum. En el segundo experimento se usó la técnica de degradabilidad ruminal in vitro de la materia seca (DMS) y de las fracciones de fibra (DFDN y DFDA) de una dieta para corderos adicionada con extracto de $C$. verum con diferente tiempo de incubación. La adición del extracto mostró efectos ( $p<$ 0.01) lineales y cuadráticos sobre la asíntota de PG (b). La adición del extracto de $C$. verum tuvo efectos lineales $(p<0.01)$ en la DIVMS. La DMS a las 24 y 48 $\mathrm{h}$ de incubación no mostró diferencias entre tratamientos. La DFDN fue menor $(\mathrm{p}<0.01)$ a las $72 \mathrm{~h}$ al adicionar el extracto de $C$. verum versus el tratamiento testigo, pero no hubo efectos significativos a las 24 y $48 \mathrm{~h}$. La DFDA del tratamiento testigo versus el extracto de $C$. verum fue significativa $(p<0.05)$ a las 24 y $72 \mathrm{~h}$. El extracto de $C$. verum modifica los parámetros de la fermentación ruminal y reduce la degradabilidad de la fibra a las $72 \mathrm{~h}$ de fermentación ruminal.

Palabras clave: Cinética, degradabilidad, materia seca, producción de gas, rumiantes.

ABSTRACT. Two experiments were conducted to evaluate the effect of different doses of Cinnamomum verum extract addition in a lamb diet on in vitro fermentation parameters and ruminal degradability. In the first experiment, the technique of in vitro gas production (PG) was carried out to a ration for lambs added with 0.0 , $0.6,1.2$ and $1.8 \mathrm{~mL} \mathrm{~g}^{-1}$ of DM of $C$. verum extract. In the second experiment, the technique of in vitro ruminal degradability of dry matter (DMD) and fiber fractions (NDFD and ADFD) of a lamb diet added with an extract of $C$. verum was carried out in different incubation times. The addition of the extract showed linear and quadratic $(p<0.01)$ effects on the PG asymptote (b). The addition of $C$. verum extract had linear $(p<0.01)$ effects on IVDMD. The DMD at 24 and $48 \mathrm{~h}$ incubation showed no difference between treatments. The NDFD was lower $(p<0.01)$ at $72 \mathrm{~h}$ when adding $C$. verum extract versus the control treatment, but there were no significant effects at 24 and $48 \mathrm{~h}$. The ADFD of the control treatment versus $C$. verum extract was significant $(p<0.05)$ at 24 and 72 h. $C$. verum extract modifies the parameters of ruminal fermentation and reduces the degradability of fiber at the end of ruminal fermentation.

Key words: Kinetics, degradability, dry matter, gas production, ruminants. 


\section{INTRODUCCIÓN}

La utilización de ionóforos como aditivos para mejorar la eficiencia de la fermentación ruminal está teniendo un impacto negativo en algunos países de la Unión Europea, debido a la trasmisión de residuos a la carne o leche (Geraci et al. 2012). Por lo que se buscan alternativas de aditivos no sintéticos para mejorar el rendimiento, la salud del animal y disminuir el impacto ambiental durante los procesos productivos con rumiantes (Honan et al. 2021). Los compuestos secundarios contenidos en algunas plantas representan una opción como aditivos alimenticios para la producción animal (Salem et al. 2012, Cobellis et al. 2016).

Los extractos de plantas son una mezcla compleja de diferentes sustancias bioquímicas, de las cuales la cantidad de metabolitos secundarios depende de la parte de la planta utilizada, tiempo de cosecha, condiciones de almacenamiento y método de extracción (Demirtas et al. 2018). La inclusión de extractos de plantas como moduladores de la cinética y fermentación ruminal en la alimentación de rumiantes reemplaza el efecto antimicrobiano de los antibióticos (Cobellis et al. 2016, Reddy et al. 2020). Se ha observado que la adición de extractos de plantas a las dietas para rumiantes genera un aumento de la digestibilidad de los nutrientes, del metabolismo proteico y de la ganancia de peso, debido a una disminución de la producción de metano entérico durante la fermentación, lo cual mejora la utilización de la energía en el animal (Cedillo et al. 2014) y aumenta la productividad (Geraci et al. 2012).

En el extracto de canela (Cinnamomun verum), el cinamaldehído es el principal compuesto del aceite esencial, cuyo efecto antimicrobiano in vitro ha sido ampliamente demostrado (Salem et al. 2021). Por lo que el cinamaldehído es una alternativa para modificar la fermentación del rumen en el ganado de carne (Mateos et al. 2013, Khorrami et al. 2015, Catalá-Gregori et al. 2019). El extracto de C. Verum se presenta como un mejorador de la eficiencia alimentaria y el crecimiento de corderos alimentados con dietas basadas en concentrados (Chaves et al. 2015). Pero el modo de acción de los aditivos de aceites esenciales y extractos de plantas sobre la microbiota del rumen siguen siendo poco conocidos (Cobellis et al. 2016). Por lo que es necesario determinar los mecanismos de acción del extracto de C. Verum sobre la fermentación microbiana ruminal, así como obtener información sobre las dosis de uso de este tipo de extractos. Por lo que el objetivo del presente trabajo fue evaluar el efecto de diferentes dosis de adición de extracto de $C$. verum en una dieta para corderos sobre los parámetros de fermentación in vitro y la degradabilidad ruminal.

\section{MATERIALES Y MÉTODOS}

\section{Localización}

Los experimentos de fermentación ruminal in vitro se realizaron en el Laboratorio de Nutrición Animal, en la Central Integral de Laboratorios de la Facultad de Ingeniería y Ciencias, de la Universidad Autónoma de Tamaulipas, en Cd. Victoria, Tamaulipas. Los animales donadores de líquido ruminal (inóculo) fueron alojados en jaulas individuales en el Campo Experimental, Posta Zootécnica "Ingeniero Herminio García González", en el municipio de Güemez, Tamaulipas.

\section{Preparación del extracto, sustrato y análisis químico}

Se utilizó un extracto a base de $C$. verum, esta especie fue seleccionada sobre sus efectos antimicrobianos y/o digestivos conocidos. El material vegetal fue adquirido en las herboristerías locales. La canela se utiliza comúnmente como producto herbal terapéutico o como especia (sazonador). La parte de la planta utilizada fue la corteza de $C$. verum para la preparación del extracto.

El método de extracción se realizó mediante la metodología descrita por Salem et al. (2012), para lo que $10 \mathrm{~g}$ molidos ( $1 \mathrm{~mm}$ de partícula) de C. verum fueron mezclados con $80 \mathrm{~mL}$ de una mezcla de solventes (10 $\mathrm{mL}$ de metanol $(99.8 / 100$, grado analítico, Fermont $\left.{ }^{\circledR}\right), 10 \mathrm{~mL}$ de etanol $(99 / 100$, de grado analítico, Fermont ${ }^{\circledR}$ ) y $80 \mathrm{~mL}$ de agua destilada. La mezcla de material de $C$. verum y solvente se conservó a temperatura ambiente $\left(25-30{ }^{\circ} \mathrm{C}\right)$ por 48 
h en frascos cerrados. Posteriormente, todos los frascos se incubaron en baño a temperatura constante de $39{ }^{\circ} \mathrm{C}$ durante una hora, e inmediatamente después se filtraron en cuatro capas de gasa, y el material colectado se almacenó a $4{ }^{\circ} \mathrm{C}$ para su uso posterior.

Se formuló una dieta integral (Tabla 1) para cumplir con los requerimientos nutricionales de ovinos en crecimiento con una ganancia diaria de peso de $200 \mathrm{~g} \mathrm{día}^{-1}$ según las recomendaciones del NRC (2007). Una muestra de la dieta se deshidrató a $65^{\circ} \mathrm{C}$ durante $48 \mathrm{~h}$ en una estufa de aire forzado, posteriormente se molió a partícula de $1 \mathrm{~mm}$ y se almacenó en frascos de plástico para la subsecuente determinación de la composición química y su utilización en las pruebas in vitro como sustrato.

Las muestras de dieta se analizaron para contenido de materia seca (MS), en estufa de aire forzado a $105{ }^{\circ} \mathrm{C}$ durante $24 \mathrm{~h}$, materia orgánica (MO), por pérdida de peso tras la calcinación a 550 ${ }^{\circ} \mathrm{C}$ durante $6 \mathrm{~h}$, y contenido de nitrógeno $(\mathrm{N})$, procedimiento Kjeldahl de acuerdo con los procedimientos descritos por la AOAC (1999). El contenido de proteína cruda (PC) se calculó multiplicando en contenido de $\mathrm{N}$ por 6.25. El contenido de fibra detergente neutro (FDN, con $\alpha$-amilasa termoestable y sulfito de $\mathrm{Na}$ ) y fibra detergente ácido (FDA) se determinaron utilizando bolsas filtro ANKOM F-57 en un analizador de fibra ANKOM ${ }^{200}$ (ANKOM Technology, Macedon, N.Y. USA). Los compuestos secundarios: fenoles totales (FT), saponinas (SAP) y la fracción acuosa (FA) en el extracto de $C$. verum fueron determinados de acuerdo con la metodología descrita por Salem et al. (2012). Los compuestos secundarios se determinaron por triplicado, $10 \mathrm{~mL}$ de extracto fue fraccionado en un embudo de separación con $20 \mathrm{~mL}$ de etilo $\left(99.7 / 100\right.$, grado analítico, Fermont $\left.{ }^{\circledR}\right)$. La determinación de los FT por desecación y cuantificación de la capa de FT. Después de la separación FT, se añadió $20 \mathrm{~mL}$ de n-butanol (99.9/100, grado analítico, Fermont ${ }^{\circledR}$ ) para fraccionar las SAP. EI resto de la solución se consideró como FA que contiene otros metabolitos secundarios como lectinas, polipéptidos y almidón (Cowan 1999).

\section{Fermentación ruminal in vitro}

La producción de gas (PG) in vitro se estimó mediante la metodología propuesta por Theodorou et al. (1994) con las modificaciones de Mauricio et al. (1999). El líquido ruminal para las pruebas de fermentación ruminal in vitro se colectó por vía esofágica de cuatro ovinos (Pelibuey, PV $24 \pm 0.3$ $\mathrm{kg}$ ) alimentados con la una dieta integral usada como sustrato (Tabla 1). La dieta integral se ofreció dos veces al día, y el agua fresca estaba disponible para los animales en todo momento durante la fase de recolección del inóculo ruminal. Se utilizó el extracto de $C$. verum a diferentes dosis: 0.0 (sin extracto), 0.6 , 1.2 y $1.8 \mathrm{~mL} \mathrm{~g}^{-1} \mathrm{MS}$ de dieta para corderos. Se pesó por quintuplicado $1 \pm 0.002 \mathrm{~g} \mathrm{MS}$ de la dieta (sustrato) y se colocó en botellas de $160 \mathrm{~mL}$ de capacidad con la adición de extracto con las dosis anteriormente mencionadas. El extracto se aplicó de forma directa sobre el sustrato dentro de las botellas $24 \mathrm{~h}$ antes de agregar solución buffer y el fluido ruminal. El contenido ruminal se obtuvo antes de la alimentación de los animales y se transportó en botellas térmicas (500 a $1000 \mathrm{~mL}$ de capacidad) del lugar de colecta hasta el laboratorio. Posteriormente, bajo condiciones de laboratorio se filtró y mantuvó a $39{ }^{\circ} \mathrm{C}$ bajo una corriente continua de $\mathrm{CO}_{2}$ hasta su uso. Una vez cumplida esta fase se adicionó a cada botella $90 \mathrm{~mL}$ de solución buffer, la cual incluye macro y microelementos, un agente reductor y resazurina como indicador de anaerobiosis (Mauricio et al. 1999). Posteriormente, cada botella fue inoculada con $10 \mathrm{~mL}$ de líquido ruminal. Se incluyeron en la prueba botellas con medio nutritivo, líquido ruminal con o sin extracto, pero sin sustrato para la corrección de gas producido a partir de pequeñas partículas presentes en el líquido ruminal. La PG acumulada $(\mathrm{mL}$ $\mathrm{g}^{-1} \mathrm{MS}$ ) se registró a las 2, 4, 6, 8, 10, 12, 15, 19, 24, 30, 36, 48 y 72 h después de la incubación de las botellas a $39^{\circ} \mathrm{C}$ en un incubador de temperatura. Al final de la incubación (72 h), el contenido de MS residual de cada botellas se filtró usando crisoles de vidrio (porosidad 1, 100 a $160 \mu \mathrm{m}$ tamaño de poro) con ayuda de una bomba de vacío. Los residuos de la fermentación fueron deshidratados en una estufa de aire forzado a $65{ }^{\circ} \mathrm{C}$ durante $24 \mathrm{~h}$ para deter- 
Tabla 1. Ingredientes y composición química $\left(\mathrm{g} \mathrm{kg}^{-1}\right.$ de MS) de la dieta para ovinos en crecimiento y concentración de compuestos secundarios del extracto de Cinnamomum verum.

\begin{tabular}{|c|c|c|}
\hline & Sustrato (dieta para ovinos) & Extracto de $C$. verum \\
\hline \multicolumn{3}{|l|}{ Ingredientes } \\
\hline Sorgo & 170 & \\
\hline Harina de soya & 150 & \\
\hline Maíz & 210 & \\
\hline Buffel & 390 & \\
\hline Melaza & 50 & \\
\hline Mezcla mineral $^{a}$ & 30 & \\
\hline \multicolumn{3}{|l|}{ Composición química } \\
\hline Proteína cruda & 142 & \\
\hline Energía metabolizable (Mcal kg-1) & 2.72 & \\
\hline Fibra detergente neutra & 351 & \\
\hline Fibra detergente ácida & 167 & \\
\hline Hemicelulosa & 183 & \\
\hline Materia orgánica & 910 & \\
\hline \multicolumn{3}{|l|}{ Compuestos secundarios ${ }^{b}$} \\
\hline Fenoles totales & & 4.43 \\
\hline Saponinas & & 0.46 \\
\hline Fracción acuosa & & 5.21 \\
\hline
\end{tabular}

minar la degradabilidad in vitro de la MS (DIVMS). El valor de la energía metabolizable (EM, Mcal kg ${ }^{-1}$ MS) se estimó de acuerdo con Menke y Steingass (1988) y la concentración de ácidos grasos de cadena corta (AGCC, mmol g ${ }^{-1} \mathrm{MS}$ ) se calculó de acuerdo con Getachew et al. (2002). La estimación de los parámetros de la cinética de producción de gas $(\mathrm{mL}$ $\mathrm{g}^{-1} \mathrm{MS}$ ) se obtuvieron con el procedimiento NLIN de SAS versión 9.2 de acuerdo con el modelo propuesto por France et al. (2000):

$$
P G_{t}=b x\left[1-e^{-c(t-L)}\right]
$$

Donde: PGt es el volumen de PG en el tiempo, $t$, b es la PG asintótica ( $\mathrm{mL} \mathrm{g}^{-1} \mathrm{MS}$ ); c es la tasa de $P G\left(h^{-1}\right)$ y $L$ es la fase lag $(h)$ y e es la base de los logaritmos naturales $(e=2.71828182)$.

\section{Degradabilidad de la materia seca y fracciones de fibra}

Se utilizó la técnica de la bolsa basada en la metodología descrita por Ørskov et al. (1980) con las modificaciones metodológicas propuestas por ANKOM Technology Corporation. Se pesaron 500 $\pm 10 \mathrm{mg}$ de MS de la dieta sustrato, misma que se utilizó en el experimento de PG, y se depositaron en bolsas filtro ANKOM-F57. Las bolsas se sellaron y colocaron en frascos de fermentación del sistema ANKOM Daisy II. Posteriormente se adicionó a cada frasco de fermentación medio nutritivo $(1600 \mathrm{~mL}$ ) (Mauricio et al. 1999) y líquido ruminal procesado (400 mL). El líquido ruminal se colectó y procesó como se describe en el experimento de $P G$ in vitro. Se usó un total de 30 bolsas por tratamiento, 24 con sustrato y seis sin sustrato para corregir la posible contaminación, colocadas dentro de cada frasco de fermentación. El extracto de C. verum se aplicó al frasco de fermentación antes de la incubación, a un volumen de $15 \mathrm{~mL}$ por frasco, que correspondía a $1.2 \mathrm{~mL} \mathrm{~g}^{-1}$ de MS de la dieta sustrato. También, se incluyó un tratamiento testigo (sin adición de extracto). Los frascos de fermentación se incubaron a temperatura de $39 \pm 0.5{ }^{\circ} \mathrm{C}$, con agitación circular constante. Se retiraron por cuadruplicado bolsas de filtro (más una bolsa vacía para corregir la contaminación microbiana) de cada frasco de fermentación a las $6,12,18,24,48$ y 72 h después de la incubación. Después del retiro, las bolsas se lavaron con agua fría durante $30 \mathrm{~min}$. Para luego deshidratarlas a 65 ${ }^{\circ} \mathrm{C}$ hasta alcanzar peso constante para determinar la degradabilidad de la MS (DMS). La degradabilidad de la FDN y FDA (DFDN, DFDA, respectivamente) se determinó a las 24, 48 y 72 h de incubación, en una unidad de análisis de fibra. En los análisis de FDN, 
se incluyó $\alpha$-amilasa termoestable, pero se omitió el sulfito de sodio.

\section{Análisis estadístico}

Todos los análisis estadísticos se realizaron con el paquete estadístico SAS versión 9.2. Las estimaciones de los parámetros de la cinética de PG (b, c y L) para cada muestra se obtuvieron con el procedimiento NLIN. Los datos de fermentación ruminal in vitro se analizaron como un diseño completamente al azar con cuatro tratamientos y cuatro repeticiones por tratamiento con el procedimiento GLM. Con las medias de los cuadrados mínimos se realizaron contrastes ortogonales para probar diferencias significativas entre el testigo y el promedio general del extracto. El efecto de la dosis del extracto de $C$. verum se evaluó utilizando polinomios ortogonales considerando efectos lineales y cuadráticos a un nivel de significancia de $p<0.05$.

La degradabilidad de la materia seca y de fracciones de fibra se analizaron como un diseño completamente al azar con dos tratamientos y cuatro repeticiones con el procedimiento GLM. Se obtuvieron los errores medios y estándar de los cuadrados mínimos, que se usaron para las comparaciones de medias múltiples con la prueba de Tukey a un nivel de significancia entre medias de $p<0.05$.

\section{RESULTADOS}

Los ingredientes y la composición química de una dieta para corderos en crecimiento y el contenido de compuestos secundarios del extracto de Cinnamomum verum se presentan en el Tabla 1. Las medias de los cuadrados mínimos de los parámetros de la cinética de producción de gas (PG) in vitro (b, c y L), EM, ácidos AGCC y DIVMS de la dieta para ovinos con diferentes dosis del extracto de $C$. verum se muestran en el Tabla 2. La adición del extracto tuvo efectos $(p<0.01)$ lineales y cuadráticos en los parámetros b, c y L (Figura 1). La adición del extracto de $C$. verum tuvo efectos lineales $(p<0.01)$ en la DIVMS. Las medias de cuadrados mínimos de producción de gas acumulada a diferentes tiempos después de la inoculación de una dieta para corderos con diferentes dosis de extracto $C$. verum se muestra en el Tabla 3. Los efectos del extracto de $C$. verum fueron significativos $(p<0.05)$ en la $P G$ acumulada a las 12,48 y $72 h$, con efectos lineales $(p<0.05)$ a las $12 \mathrm{~h}$ y cuadráticos $(\mathrm{p}<0.01)$ a las 48 y $72 \mathrm{~h}$.

Los resultados del segundo experimento muestran que durante las primeras $12 \mathrm{~h}$ de incubación no hay una diferencia significativa en la DMS entre el tratamiento testigo y el extracto de $C$. verum (Tabla 4). A las $18 \mathrm{~h}$ de incubación, la DMS media del tratamiento con extracto de $C$. verum fue de $481 \mathrm{mg} \mathrm{g}^{-1}$ de $\mathrm{MS}$, que es significativamente ( $p<0.01)$ menor que la DMS de la dieta testigo (521 $\mathrm{mg} \mathrm{g}^{-1}$ de MS). A las $72 \mathrm{~h}$ de incubación el tratamiento testigo tuvo el mayor $(p=0.0263)$ valor de DMS (774 $\mathrm{mg} \mathrm{g}^{-1}$ de MS). La DMS a las 24 y 48 $h$ de incubación no hubo diferencia significativa entre tratamientos. Los valores de la degradabilidad de la FDN (DFDN) y ADF (DFDA) se presentan en el Tabla 5. Existe una menor $(p<0.01)$ DFDN a las $72 \mathrm{~h}$ con el extracto versus el tratamiento testigo, pero no hubo efectos significativos a las 24 y $48 \mathrm{~h}$. La DFDA del tratamiento testigo versus extracto de $C$. verum fue significativa $(p<0.05)$ a las 24 y $72 h$.

\section{DISCUSIÓN}

La microbiota ruminal es esencial para los rumiantes por la capacidad que tienen de utilizar un alimento de baja calidad y convertirla en proteína de alta calidad. El extracto de C. verum modificó los parámetros de la fermentación ruminal in vitro, lo que indica que los compuestos bioactivos de la canela pueden alterar la cinética de PG y DIVMS, sin afectar la EM y la producción de AGCC. El criterio principal para seleccionar un extracto de plantas en la nutrición animal es que incremente o no cambie la concentración de AGCC (Cardozo et al. 2005). Al respecto, Busquet et al. (2005) reportan que concentraciones altas de extracto de canela (300 y $3000 \mathrm{mg} \mathrm{L}^{-1}$ ) no afecta el metabolismo del nitrógeno, pero sí disminuye de forma significativa la proporción molar de ácidos grasos volátiles comparado con el tratamiento testigo, pero los autores sugieren que puede ser utilizado como modulador 
Tabla 2. Cinética de producción de gas in vitro, energía metabolizable, ácidos grasos de cadena corta y degradabilidad in vitro de la materia seca de una dieta para corderos con diferentes dosis de extracto de canela (Cinnamomum verum).

\begin{tabular}{|c|c|c|c|c|c|c|c|c|}
\hline & \multicolumn{4}{|c|}{ Dosis (mL g $\left.{ }^{-1} \mathrm{MS}\right)$} & \multirow[t]{2}{*}{ EEM } & \multicolumn{3}{|c|}{$\mathrm{p}$-valor del contraste } \\
\hline & 0.0 & 0.6 & 1.2 & 1.8 & & Testigo vs Extracto & Lineal & Cuadrático \\
\hline $\mathrm{b}$ & 193.18 & 348.80 & 343.58 & 339.70 & 13.66 & $<0.0001$ & $<0.0001$ & $<0.0001$ \\
\hline c & 0.0208 & 0.0104 & 0.0111 & 0.0105 & 0.0007 & $<0.0001$ & $<0.0001$ & $<0.0001$ \\
\hline $\mathrm{L}$ & 3.32 & 3.67 & 3.73 & 3.56 & 0.047 & $<0.0001$ & 0.0037 & 0.0002 \\
\hline EM & 11.33 & 11.18 & 11.51 & 11.03 & 0.210 & 0.7077 & 0.5561 & 0.4571 \\
\hline AGCC & 1.35 & 1.33 & 1.38 & 1.30 & 0.034 & 0.7073 & 0.5520 & 0.4488 \\
\hline DIVMS & 741.8 & 773.3 & 801.3 & 801.0 & 10.47 & 0.0014 & 0.0009 & 0.1554 \\
\hline
\end{tabular}

b: Asíntota de producción de gas ( $\mathrm{mL} \mathrm{g}^{-1}$ de MS), c: tasa de producción de gas $\left(\mathrm{h}^{-1}\right)$, L: fase lag (h), DIVMS: degradabilidad in vitro de la MS ( $\mathrm{mg} \mathrm{g}^{-1}$ de MS), EM: energía metabolizable (MJ $\mathrm{kg}^{-1}$ de MS), AGCC: ácidos grasos de cadena corta (mmol), EEM: Error estándar de la media.

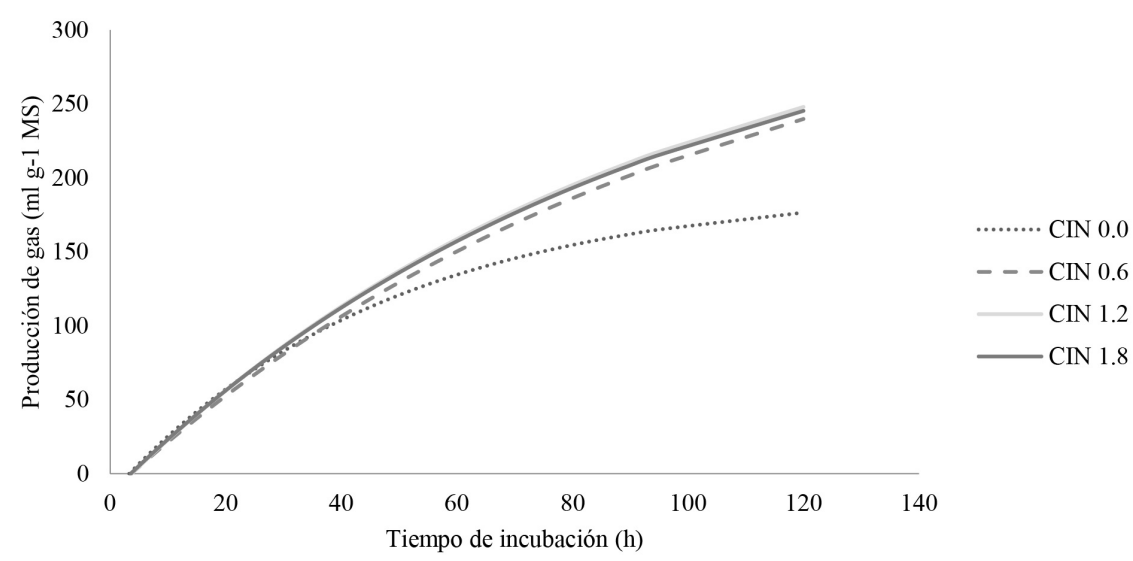

Figura 1. Producción acumulada de gas $\left(\mathrm{mL} \mathrm{g}^{-1}\right.$ de MS) de la fermentación ruminal in vitro de una dieta para cordero con extracto de canela (Cinnamomum verum) $(\mathrm{CIN})$ en diferentes dosis $(0.0,0.6$, $1.2,1.8 \mathrm{~mL} \mathrm{~g}^{-1}$ ).

Tabla 3. Producción de gas acumulada ( $\mathrm{mL} \mathrm{g}^{-1}$ de MS) a diferentes tiempos después de la inoculación de una dieta para corderos con diferentes dosis de extracto de canela (Cinnamomum verum).

\begin{tabular}{clllllllll}
\hline & \multicolumn{3}{c}{ Dosis $\left(\mathrm{mL} \mathrm{g}^{-1} \mathrm{MS}\right)$} & \multirow{2}{*}{ EEM } & \multicolumn{3}{c}{$\mathrm{p}$-valor del contraste } \\
\cline { 2 - 4 } \cline { 8 - 9 } & 0.0 & 0.6 & 1.2 & 1.8 & & Testigo vs Extracto & Lineal & Cuadrático \\
\hline $12 \mathrm{~h}$ & 31.82 & 28.80 & 30.00 & 28.50 & 0.85 & & 0.0151 & 0.0373 & 0.3648 \\
$24 \mathrm{~h}$ & 67.30 & 66.03 & 68.80 & 64.84 & 1.70 & & 0.7087 & 0.5543 & 0.4493 \\
$48 \mathrm{~h}$ & 116.45 & 128.03 & 132.50 & 125.30 & 2.30 & 0.0041 & 0.0383 & 0.0081 \\
$72 \mathrm{~h}$ & 146.31 & 176.40 & 181.40 & 172.32 & 4.08 & & $<0.0001$ & 0.0007 & 0.0004 \\
\hline
\end{tabular}

del crecimiento de la microbiota ruminal. Uno de los principales compuestos de la canela es el cinamaldehído, compuesto no fenólico, con diferente modo de acción que los compuestos fenólicos, ya que actúa en el citoplasma $u$ organelos de las bacterias (Helander et al. 1998, Salem et al. 2021); siendo las bacterias gram-positivas las más sensibles a la inhibición de este compuesto (Smith-Palmer et al. 1998). Pero algunos estudios han demostrado que el cinamaldehído en su forma más pura también es efectivo contra bacterias gram-negativas (Kim et al. 1995). El cinamaldehído puede tener acceso al protoplasma por la membrana externa atravesando las porinas (Nikaido 1994), mientras que algunos estudios sugieren que el grupo carbonilo puede ser el sitio activo para esta acción (Wendakon y Sakaguchi 1995). Al respecto, Fraser et al. (2007) en un trabajo con aceite de canela no detectó efecto significativo en la PG in vitro, pero la concentración de metano fue menor con aceite de canela. Lo que es similar 
Tabla 4. Degradabilidad de la materia ( $\mathrm{mg} \mathrm{g}^{-1}$ de MS) seca a diferentes tiempos de incubación de una dieta para corderos con y sin extracto de canela (Cinnamomum verum).

\begin{tabular}{lllll}
\hline & \multicolumn{2}{l}{ Extracto de $C$. verum $\left(\mathrm{mL} \mathrm{g}^{-1} \mathrm{MS}\right)$} & \multirow{2}{*}{ EEM } & Probabilidad \\
\cline { 2 - 4 } Tiempo & 0.0 (Testigo) & 1.2 & & \\
\hline $6 \mathrm{~h}$ & 381 & 389 & 0.51 & 0.3210 \\
$12 \mathrm{~h}$ & 440 & 435 & 0.52 & 0.4964 \\
$18 \mathrm{~h}$ & $521^{a}$ & $481^{b}$ & 0.27 & $<0.0001$ \\
$24 \mathrm{~h}$ & 603 & 610 & 1.03 & 0.6503 \\
$48 \mathrm{~h}$ & 722 & 714 & 0.38 & 0.1972 \\
$72 \mathrm{~h}$ & $774^{a}$ & $742^{b}$ & 0.77 & 0.0263 \\
\hline
\end{tabular}

EEM: Error estándar de la media, ${ }^{a b}$ Medias con diferente superíndice son diferentes $(p<0.05)$.

Tabla 5. Degradabilidad de la fibra detergente neutro y ácido $\left(\mathrm{mg} \mathrm{g}^{-1}\right.$ de MS) a diferentes tiempos de incubación de una dieta para corderos con y sin extracto de canela (Cinnamomum verum).

\begin{tabular}{cllll}
\hline \multirow{2}{*}{ Tiempo } & \multicolumn{2}{l}{ Extracto de C. verum $\left(\mathrm{mL} \mathrm{g}^{-1} \mathrm{MS}\right)$} & \multirow{2}{*}{ EEM } & Probabilidad \\
\cline { 2 - 3 } & 0.0 (Testigo) & 1.2 & & \\
\hline DFDN 24 h & 430 & 403 & 1.03 & 0.1155 \\
48 h & 597 & 607 & 0.45 & 0.1991 \\
72 h & $681^{a}$ & $639^{b}$ & 0.72 & 0.0062 \\
DFDA 24 h & $256^{a}$ & $227^{b}$ & 0.84 & 0.0496 \\
48 h & 443 & 449 & 1.02 & 0.6527 \\
$72 \mathrm{~h}$ & $561^{a}$ & $477^{b}$ & 0.75 & 0.0002
\end{tabular}

DFDN: degradabilidad in vitro de la fibra detergente neutro, DFDA: degradabilidad in vitro de la fibra detergente ácido, EEM: Error estándar de la media, ${ }^{a b}$ Medias con diferente superíndice son diferentes $p<0.05$.

a lo encontrado en el presente estudio en donde se observaron efectos significativos en la PG acumulada con respecto al testigo, con tendencias cuadráticas a las dosis en los tiempos finales de la fermentación. Lo que puede indicar que el modo de acción antimicrobiana del extracto tarda entre 40 y $48 \mathrm{~h}$ para empezar a interactuar con los microorganismos del medio, debido a que el cinamaldehído atraviesa de forma más profunda la célula bacteriana que otros compuestos fenólicos, lo que toma más tiempo para causar lisis en la célula (Helander et al. 1998). Mientras que Hart et al. (2008) mencionan que los extractos acuosos pueden tener diferente bioactividad que aquellos extraídos con solventes alcohólicos por la naturaleza volátil de los compuestos.

En el segundo experimento en las primeras 12 $\mathrm{h}$ de incubación no se observaron diferencias significativas para la DMS entre el testigo y el extracto de C. verum. A las 18 y $72 \mathrm{~h}$ de incubación la DMS con extracto de $C$. verum fue de menor que la dieta testigo. Esto se puede atribuir a la naturaleza del extracto, ya que los compuestos bioactivos pudieron afectar la microbiota ruminal y, por lo tanto, se alteró la DMS pudiendo causar disminución de la población bacteriana (Cobellis et al. 2016). En otro estudio realizado con una mezcla de aceites de tomillo (Thymus vulgaris), orégano (Origanum vulgare), canela (Cinnamomum verum) y limón (Citrus limonum), se encontró que la combinación de estos aceites esenciales tiene efectos sinérgicos que dependen de la dosis (Lin et al. 2012). Se ha reportado también que la reducción en la producción de metano tiene una influencia mínima en la degradabilidad del alimento (Lin et al. 2012). Esta diferencia se puede atribuir al método de extracción y a la actividad antimicrobiana entre aldehídos y aceites con fenoles (Macheboeuf et al. 2008). La aplicación del extracto de $C$. verum no afectó la DFDN y DFDA, con excepción de los resultados de la hora 72 , en donde se encontró que la degradabilidad de las fracciones de fibra fue menor con el extracto de canela, lo que sugiere que las bacterias celulolíticas y hemicelulolíticas no son afectadas por el extracto. Sin embargo, otros estudios han reportado que $C$. verum mejoró la degradabilidad 
de la MS y la degradabilidad de la FDN después de 24 horas de fermentación. Esto se puede atribuir a que algunas poblaciones bacterianas son más sensibles que otras (Righi et al. 2017). También reporta especificidad antimicrobiana de los compuestos de la canela contra Prevotella spp. (Ferme et al. 2004). Al respecto, Righi et al. (2017) concluyen que las bacterias amilolíticas son más susceptibles a la actividad antimicrobiana de $C$. verum que las bacterias celuIolíticas.

Con otros extractos y aceites esenciales, se menciona que la combinación de aceites esenciales con presencia de cinamaldehído y eugenol en cantidades elevadas, inhiben ciertos microorganismos evaluados como protozoarios, hongos y dos bacterias celulolíticas (Fibrobacter succinogenes y Ruminococcus flavefaciens) (Lin et al. 2012). La diferencia entre los efectos puede deberse a la estructura bioquímica de las soluciones, tipos de planta, nivel de dosis y método de extracción (Ramar y Ponnampalam 2010).

\section{CONCLUSIONES}

El extracto de C. verum aplicado a diferentes dosis modifica los parámetros de fermentación ruminal de la dieta de ovinos. La adición de $1.2 \mathrm{~mL} \mathrm{~g}^{-1}$ de MS del extracto de $C$. verum mejoró los valores de la DIVMS. La adición del extracto de $C$. verum no mejoró la DMS a diferentes tiempos de incubación comparado con el tratamiento testigo. La degradabilidad de la FDN y FDA se reduce a las $72 \mathrm{~h}$ al agregar el extracto de $C$. verum.

\section{LITERATURA CITADA}

AOAC (1999) Official Methods of Analysis. Association of Official Analytical Chemists, INC. USA. 672p.

Busquet M, Calsamiglia S, Ferret A, Kamel C (2005) Screening for effect of plant extracts and active compounds of plants on dairy cattle rumen microbial fermentation in a continuous culture system. Animal Feed Science and Technology 123-124: 597-613.

Cardozo PW, Calsamiglia S, Ferret A, Kamel C (2005) Screening for the effects of natural plant extracts at different $\mathrm{pH}$ on in vitro rumen microbial fermentation of a high-concentrate diet for beef cattle. Journal of Animal Science 83: 2572-2579.

Catalá-Gregori P, García V, Hernández F, Madrid J, Megías MD, Orengo J (2019) Efecto del cinamaldehído en la degradabilidad ruminal in vitro y la producción de ácidos grasos volátiles. Cuban Journal of Agricultural Science 53: 361-372.

Cedillo J, Vázquez-Armijo JF, González-Reyna A, Salem AZM, Kholif AE, Hernández-Meléndez J, MartínezGonzález JC, Jiménez RM de O, Rivero N, López D (2014) Effects of different doses of Salix babylonica extract on growth performance and diet in vitro production in Pelibuey growing lambs. Italian Journal of Animal Science 13: 3165.

Chaves AV, Dugan MER, Stanford K, Gibson LL, Bystrom LM, McAllister TA (2015) A dose-response of cinnamaldehyde supplementation on intake, ruminal fermentation, blood metabolites, growth performance, and carcass characteristics of growing lambs. Livestock Science 141: 213-220.

Cobellis M, Trabalza-Marinucci M, Yu Z (2016) Critical evaluation of essential oils as rumen modifiers in ruminant nutrition: A review. Science of the Total Environment 545: 556-568.

Cowan MM (1999) Plant products as antimicrobial agents. Clinical Microbiology Reviews 12: 564-582.

Demirtas A, Ozturk H, Piskin I (2018) Overview of plant extracts and plant secondary metabolites as alternatives to antibiotics for modification of ruminal fermentation. Ankara Üniversitesi Veteriner Fakültesi Dergisi 65: 213-217. 
Ferme D, Banjac M, Calsamiglia S, Busquet M, Kamel C, Avguštin G (2004) The effects of plant extracts on microbial community structure in a rumen-simulating continuous-culture system as revealed by molecular profiling. Folia Microbiology 49: 151-155.

France J, Dijkstra J, Dhanoa MS, López S, Bannink A (2000) Estimating the extent of degradation of ruminant feeds from a description of their gas production profiles observed in vitro derivation of models and other mathematical considerations. British Journal of Nutrition 83: 143-150.

Fraser GR, Chaves AV, Wang Y, McAllister TA, Beauchemin KA, Benchaar C (2007) Assessment of the effects of cinnamon leaf oil on rumen microbial fermentation using two continuous culture systems. Journal of Dairy Science 90: 2315-2328.

Geraci JI, Garciarena AD, Gagliostro GA, Beauchemin KA, Colombatto D (2012) Plants extracts containing cinnamaldehyde, eugenol and capsicum oleoresin added to feedlot cattle diets: Ruminal environment, short term intake pattern and animal performance. Animal Feed Science and Technology 176: 123-130.

Getachew G, Makkar HPS, Becker K (2002) Tropical browses: contents of phenolics compounds, in vitro gas production and stoichiometric relationship between short chain fatty acid and in vitro gas production. The Journal of Agricultural Science 139: 341-352.

Hart KJ, Yáñez-Ruiz DR, Duval SM, McEwan NR, Newbold CJ (2008) Plant extracts to manipulate rumen fermentation. Animal Feed Science and Technology 147: 8-35.

Helander IM, Alakomi H, Latva-Kala K, Mattila-Sandholm T, Pol I, Smid EJ, Gorris LGM, von Wright A (1998) Characterization of the action of selected essential oil components on gram-negative bacteria. Journal of Agriculture and Food Chemistry 46: 3590-3595.

Honan M, Feng X, Tricarico JM, Kebreab E (2021) Feed additives as a strategic approach to reduce enteric methane production in cattle: modes of action, effectiveness and safety. Animal Production Science. DOI: 10.1071/AN20295.

Khorrami B, Vakili AR, Danesh-Mesgarana M, Klevenhusenb F (2015) Thyme and cinnamon essential oils: Potential alternatives for monensin as a rumen modifier in beef production systems. Animal Feed Science Technology 200: 8-16.

Kim J, Marshall MR, Wei C (1995) Antibacterial activity of some essential oil components against five foodborne pathogens. Journal of Agricultural and Food Chemistry 43: 2839-2845.

Lin B, Lu Y, Wang JH, Liang Q, Liu JX (2012) The effects of combined essential oils along with fumarate on rumen fermentation and methane production in vitro. Journal of Animal and Feed Sciences 21: 198-210.

Macheboeuf D, Morgavi DP, Papon Y, Mousset JL, Arturo-Schaan M (2008) Dose-response effect of essential oils on in vitro fermentation activity of the rumen microbial population. Animal Feed Science and Technology 145: 335-350.

Mateos I, Ranilla MJ, Tejido ML, Saro C, Kamel C, Carro MD (2013) The influence of diet type (dairy versus intensive fattening) on the effectiveness of garlic oil and cinnamaldehyde to manipulate in vitro ruminal fermentation and methane production. Animal Production Science 53: 299-307.

Mauricio RR, Mould FL, Dhanoa MS, Owen E, Channa KS, Theodorou MK (1999) Semi-automated in vitro gas production technique for ruminant feedstuff evaluation. Animal Feed Science and Technology 79: 321-330.

Menke KH, Steingass H (1988) Estimation of the energetic feed value obtained from chemical an analysis and in vitro gas production using rumen fluid. Animal Research and Development 28: 7-55. 
Nikaido H (1994) Prevention of drug access to bacterial targets: permeability barriers and active efflux. Science 264: 382-388.

NRC (2007) Nutrient requirements of small ruminants. Sheeps, goats, cervids and new world camelids. National Academy Press, Washington, USA. 347p.

Ørskov ER, De B Hovell FD, Mould F (1980) The use of the nylon bag technique for the evaluation of feedstuffs. Tropical Animal Production 53: 195-213.

Ramar PS, Ponnampalam G (2010) Therapeutic potential of plants as anti-microbials for drug discovery. Evidence Based Complementary and Alternative Medicine 7: 283-294.

Reddy PRK, Elghandour MMMY, Salem AZM, Yasaswini D, Reddy PPR, Reddy AN, Hyder I (2020) Plant secondary metabolites as feed additives in calves for antimicrobial stewardship. Animal Feed Science and Technology 264: 114469. DOI: 10.1016/j.anifeedsci.2020.114469.

Righi F, Simoni M, Foskolos A, Beretii V, Sabbioni A, Quarantelli A (2017) in vitro ruminal dry matter and neutral detergent fibre digestibility of common feedstuffs as affected by the addition of essential oils and their active compounds. Journal of Animal and Feed Sciences 26: 204-212.

Salem AZM, López S, Robinson PH (2012) Plant bioactive compounds in ruminant agriculture - Impacts and opportunities. Animal Feed Science and Technology 176: 1-202.

Salem MZM, EL-Hefny M, Ali HM, Abdel-Megeed A, El-Settawy AAA, Böhm M, Mansour MMA, Salem AZM (2021) Plants-derived bioactives: Novel utilization as antimicrobial, antioxidant and phytoreducing agents for the biosynthesis of metallic nanoparticles. Microbial Pathogenesis 158: 105107.

Smith-Palmer A, Stewart J, Fyfe L (1998) Antimicrobial properties of plant essential oils and essences against five important food-borne pathogens. Letters in Applied Microbiology 26: 118-122.

Theodorou MK, Williams BA, Dhanoa MS, Mcallan AB, France J (1994) A Simple gas production method using a pressure transducer to determine the fermentation kinetics of ruminant feeds. Animal Feed Science and Technology 48: 185-197.

Wendakon CN, Sakaguchi M (1995) Inhibition of amino acid decarboxylase activity of Enterobacter aerogenes by active components in spices. Journal of Food Protection 58: 280-283. 